See Article page 1093.

\section{Commentary: Multiple arterial grafting seems promising, but where is the proof of a long-term survival benefit in women?}

\author{
Peter D. Drevets, MD, ${ }^{\mathrm{a}}$ and \\ Richard Lee, MD, JD, MBA ${ }^{b}$
}

In most studies, arterial grafts have greater patency than venous grafts. ${ }^{1}$ A growing body of data supports improved survival with the use of multiple arterial grafting (MAG) in coronary bypass surgery (CABG) using either bilateral internal thoracic arterial conduits or radial artery in combination with left internal thoracic artery. Data have also demonstrated that women undergoing $\mathrm{CABG}$ have worse outcomes than men. ${ }^{2}$ Can women undergoing CABG with multiple arterial grafts have improved outcomes? This is where the data become scarce. Robinson and colleagues ${ }^{3}$ attempt to address this question in this edition of the Journal.

The authors performed a meta-analysis of propensitymatched CABG outcome studies in which both MAG was used and sex specified in results. Six existing studies met criteria and included a total of 32,793 women, of whom 25,714 received single arterial graft and 7079 MAG. $^{3}$ The results lead the authors to conclude that women receiving MAG have an improved long-term survival rate and decreased rate of myocardial infarction without an increase in operative mortality.

Unfortunately, the limitations of the study prevent us from sharing this perspective. When analyzing the 3 largest included studies, which provide the bulk of the data used in the meta-analysis, the long-term survival benefit is not seen. The authors acknowledge this discrepancy and recognize that the survival benefit is directly dependent on the smaller

\footnotetext{
From the ${ }^{\mathrm{a}}$ Department of Surgery, and ${ }^{\mathrm{b}}$ Division of Cardiothoracic Surgery, Medical College of Georgia, Augusta University, Augusta, Ga.

Disclosures: The authors reported no conflicts of interest.

The Journal policy requires editors and reviewers to disclose conflicts of interest and to decline handling or reviewing manuscripts for which they may have a conflict of interest. The editors and reviewers of this article have no conflicts of interest.

Received for publication Aug 11, 2021; revisions received Aug 11, 2021; accepted for publication Aug 12, 2021; available ahead of print Aug 19, 2021.

Address for reprints: Richard Lee, MD, JD, MBA, Division of Cardiothoracic Surgery, Augusta University, 1120 15th St, BA-4300, Augusta, GA 30912 (E-mail: ricklee@augusta.edu).

J Thorac Cardiovasc Surg 2023;165:1102-3

$0022-5223 / \$ 36.00$

Copyright $($ c 2021 by The American Association for Thoracic Surgery

https://doi.org/10.1016/j.jtcvs.2021.08.041
}

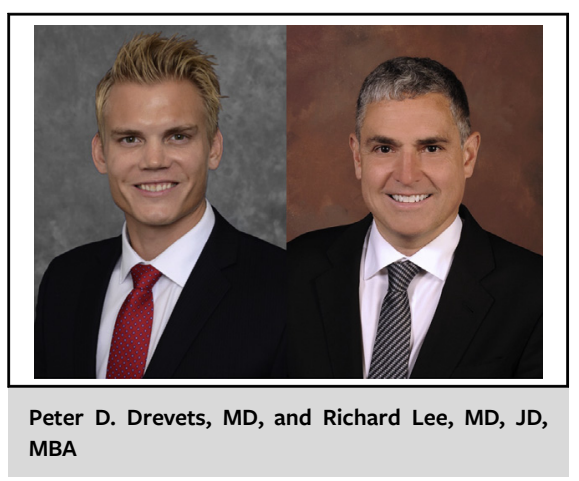

CENTRAL MESSAGE

Large studies of women under-

going bypass grafting with multi-

ple arterial grafts do not show

the same long-term survival

benefit seen in smaller studies.

High-quality randomized trials

are needed.

trials. The largest trial included 13,146 women compared with a combined total of 2883 women in smallest 3 trials. ${ }^{3}$ If a survival benefit is seen only in the smallest trials that provide the minority of patients, are the studies comparable enough to derive meaningful conclusions?

As with all propensity-matched studies, there is an inherent risk of selection bias that can be amplified in the meta-analysis. Primary data from patients and randomized trials may provide more definitive answers. Within the included studies, discrepancies in the follow-up periods and multiple surgeons using different techniques complicate the conclusion. For example, in the study by Lawton and colleagues, ${ }^{4}$ radial $\mathrm{T}$-grafts were used in all patients and procedures performed by a select group of surgeons. In comparison, Gaudino and colleagues ${ }^{5}$ used the New York database, which likely included numerous surgeons with multiple grafting techniques.

Use of the left internal thoracic artery has increased to become a standard conduit. Alternatively, MAG, including the use of radial arterial conduits, has not seen a similar increase in use despite data suggesting greater long-term patency than venous grafts and right internal thoracic artery conduits. ${ }^{6}$ The ability to definitively demonstrate an improved long-term survival remains elusive, as evidenced in the 10-year data from the Arterial Revascularisation Trial (ART), which did not demonstrate a survival benefit. ${ }^{7}$ 
Perhaps high-quality studies with rigorous, standardized criteria in technique and graft use will produce more actionable conclusions. While we do not believe this study to demonstrate a clear survival benefit in women undergoing CABG with MAG, we do believe that randomized trials are needed. The results of the ongoing ROMA trial (Randomized Comparison of the Clinical Outcome of Single vs Multiple Arterial Grafts) are eagerly awaited.

\section{References}

1. Buxton BF, Hayward PA, Raman J, Moten SC, Rosalion A, Gordon I, et al. Longterm results of the RAPCO trials. Circulation. 2020;142:1330-8.

2. Guru V, Fremes SE, Tu JV. Time-related mortality for women after coronary artery bypass graft surgery: a population-based study. J Thorac Cardiovasc Surg. 2004; 127:1158-65.

3. Robinson NB, Lia H, Rahouma M, Audisio K, Soletti G Jr, Demetres M, et al. Coronary artery bypass with single versus multiple arterial grafts in women: a meta-analysis of propensity-matched studies. J Thorac Cardiovasc Surg. 2023; 165:1093-8.

4. Lawton JS, Barner HB, Bailey MS, Guthrie TJ, Moazami N, Pasque MK, et al Radial artery grafts in women: utilization and results. Ann Thorac Surg. 2005; 80:559-63.

5. Gaudino M, Samadashvili Z, Hameed I, Chikwe J, Girardi L, Hannan E. Differences in long-term outcomes after coronary artery bypass grafting using single vs multiple arterial grafts and the association with sex. JAMA Cardiology. 2021; 6:401-9.

6. El Bardissi AW, Aranki SF, Sheng S, O’Brien SM, Greenberg CC, Gammie JS Trends in isolated coronary artery bypass grafting: an analysis of the Society of Thoracic Surgeons adult cardiac surgery database. J Thorac Cardiovasc Surg. 2012; 143:273-81.

7. Gaudino M, Bakaeen FG, Benedetto U, Di Franco A, Fremes S, Glineur D, et al Arterial grafts for coronary bypass: a critical review after the publication of ART and RADIAL. Circulation. 2019;140:1273-84.

8. Gaudino M, Alexander JH, Bakaeen FG, Ballman K, Barili F, Calafiore AM, et al Randomized comparison of the clinical outcome of single versus multiple arteria grafts: the ROMA trial-rationale and study protocol. Eur J Cardiothorac Surg. 2017;52:1031-40. 